\title{
THE REDUCTION OF STRESS CONCENTRATION IN A UNI-AXIALLY LOADED INFINITE WIDTH RECTANGULAR ISOTROPIC/ORTHOTROPIC PLATE WITH CENTRAL CIRCULAR HOLE BY COAXIAL AUXILIARY HOLES
}

\author{
JAIN N.K. \\ Department of Applied Mechanics, National Institute of Technology, \\ Raipur (C.G.)-492010, India. \\ nkjmanit@rediffmail.com,nkjnitrr@rediffmail.com
}

\begin{abstract}
A comprehensive plane stress finite element study is made for reduction of stress concentration factor (SCF) in a uni-axially loaded infinite width rectangular isotropic/orthotropic plate with central circular hole. The finite element formulation is carried out by the ANSYS package. With the help of present work, stress concentration can be reduced up to $24.4 \%$ in an isotropic and $31 \%$ in an orthotropic plate by introducing four coaxial auxiliary holes on either side of main hole. The study reveals that the introduction of these holes helps to smooth flow of the tensile stresses passes through the main hole and results, a reduction in stress concentration factor. With such reduction in maximum stress levels, the improvement in fatigue life of a component can be significant.
\end{abstract}

ABSTRAK: Satu kajian komprehensif tentang unsur terhingga telah dibuat keatas factor pemusatan tegangan bagi plat isotropic/ortotropik segi empat tepat lebar infinit yang dimuat secara uni-aksial berlubang pusat bulat. Rumusan unsur finit telah dibuat menggunakan pakej ANSYS. Dengan kajian masa kini, pemusatan tegangan dapat dikurangkan sehingga $24.4 \%$ dalam plat isotropik and $31 \%$ dalam plat ortotropik dengan membuat empat lubang auksiliari sepaksi di kedua belah lubang utama. Kajian ini menunjukkan penggunaan empat lubang ini telah melicinkan aliran tegasan tegangan melalui lubang utama. Ini mengakibatkan pengurangan factor pemusatan tegangan. Dengan pengurang tahap tegangan maksimum ini peningkatan hayat kelesuan komponen boleh menjadi signifikan.

KEYWORDS: stress concentration factor; finite element method; plate; composite

\section{INTRODUCTION}

An infinite width rectangular isotropic/orthotropic plate with central circular hole have found widespread applications in various fields of engineering such as aerospace, marine, automobile and mechanical. Stress concentration arises from any abrupt change in geometry of plate under loading. As a result, stress distribution is not uniform throughout the cross section. Failures such as fatigue cracking and plastic deformation frequently occur at points of stress concentration. Hence, for the design of a plate with central circular hole, stress concentration factor plays an important role and accurate knowledge of stresses and stress concentration factor at the edges of hole under in plane or transverse loading are required. Analytical solutions are available in the literature for prediction of 
IIUM Engineering Journal, Vol. 12, No. 6, 2011: Special Issue in Science and Ethics

Jain

SCF in different types of abrupt changes in shape, but there are limited methods for reduction in $\mathrm{SCF}$.

Meguid [1] presented a technique for reducing stress concentration factor by introducing defence hole system in a uni-axially loaded plate with two coaxial holes by finite element method, where reduction in SCF ranging from 7.5 to $11 \%$ maximum have been achieved. But to achieve the maximum possible reduction, these auxiliary holes have to be introducing very near to the original holes, which is not practically possible in all cases. Giare et al. [2] presented a method for the reduction of stress concentration around the main hole in an isotropic plate by using a ring of composite material around the main hole, method is not suitable for all designing conditions and also no techniques were presented for reduction in SCF for orthotropic plate. Providakis and Sotiropoulos [3] have developed a boundary element approach to the reduction in stress concentration factor in visco-plastic plates by multiple holes. Tenchev et al. [4] presented a design procedure for reducing stress concentration around holes in laminated composite by increasing the thickness in this area. Younis [5] investigated by reflected photoelasticity method that the assembly stress contributes to reducing stresses around the holes in a plate. Mahiou and Bekaou [6] studied for local stress concentration and for the prediction of tensile failure in unidirectional composites. Toubal et al. [7] studied experimentally for stress concentration in a circular hole in composite plate. $\mathrm{Wu}$ and $\mathrm{Mu}$ [8] analysed stress concentrations for isotropic/orthotropic plates and cylinders with a circular hole by finite element method. Peterson [20] has developed good theory and charts on the basis of mathematical analysis and presented excellent mythology in graphical form for evaluation of stress concentration factors, but no techniques were presented for reduction of SCF.

This paper is concerned with the reduction of SCF in isotropic and orthotropic infinite width rectangular plates with central circular hole under in-plane static loading. In general stress concentration factor can be reduced up to $12-18 \%$ by two coaxial auxiliary holes on either side of the main hole, to achieve the maximum possible reduction; these auxiliary holes are to be introducing very near to the original hole, which is not practically possible. It has been seen that the reduction in SCF at the edges of main hole become directly proportional to diameter of auxiliary holes, increasing the diameter of auxiliary holes results in reduction of normal stress $\left(\sigma_{\mathrm{x}}\right)$ at the edges of main hole, but this is also accompanied by an increase of $\sigma_{\mathrm{x}}$ at the edges of auxiliary holes. At a certain diameter of auxiliary holes, $\sigma_{\mathrm{x}}$ at the edges of auxiliary holes attained more than $\sigma_{\mathrm{x}}$ at the edges of main hole i.e. maximum value of $\sigma_{\mathrm{x}}$ is shifted from edges of main hole to edges of auxiliary holes. This problem can avoid by introducing two more coaxial holes on either side of first two coaxial holes and the diameter of first two auxiliary holes can increase more. This results more reduction in stress concentration. The work has been done firstly for isotropic plates, and then study is further expanded for orthotropic plates.

This work is most appreciated in aerospace and marine industry where the introduction of holes will not only reduce the stress concentration around main hole, but also reduce the weight of the components. This study will also provide guidelines technique to designer for reduction of stress concentration up to maximum level.

\section{DESCRIPTION OF PROBLEM}


To study the influence of auxiliary holes upon the stress concentration around the main hole, three models $A, B$ and $C$ are described in Fig. 1, where model $A$ is basic model (a plate with central circular hole of diameter $D$ ), model $B$ is modification of model $A$ (plate with two coaxial auxiliary holes of diameter $D_{l}$, numbered as auxiliary hole 1) and model $C$ is modification of model $B$ (plate with four coaxial auxiliary holes) i.e. two more coaxial auxiliary holes of diameter $D_{2}$ (numbered as auxiliary hole 2) are created in model $B$. The centre distance between main hole and auxiliary hole 1 is taken as $X$ and the centre distance between auxiliary hole 1 and auxiliary hole 2 is taken as $0.8 X$. All the details of dimensions are described in Fig 1. A plate under in-plane static uniformly distributed load of $P$, is analyzed by finite element method for $D / A$ ratio of 0.1 , where $A$ is plate width. The dimensions are selected such a way that it can be considered as infinite width plate.

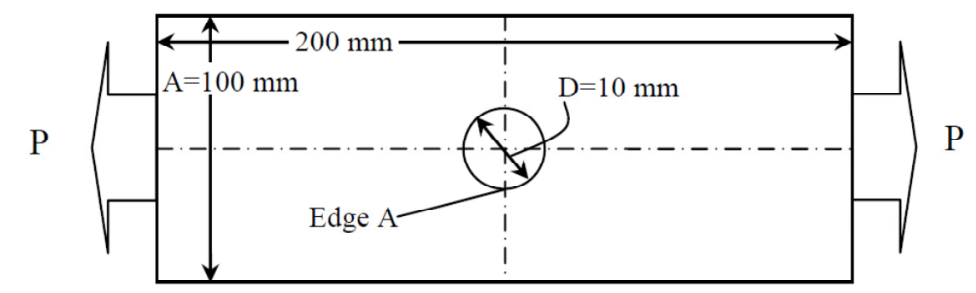

(a) Model $A$ (Basic plate with central circular hole of diameter $D$ ).

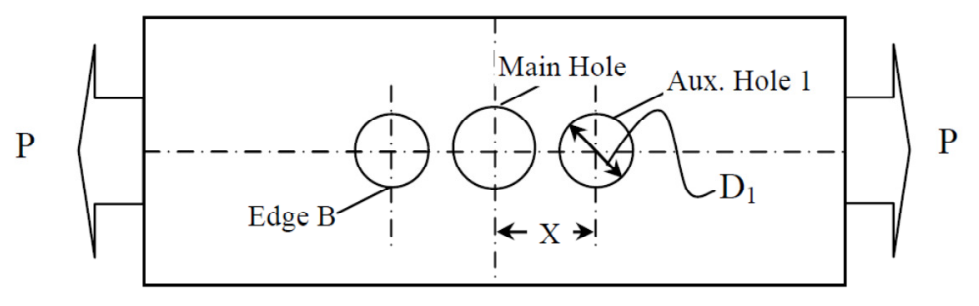

(b) Model $B$

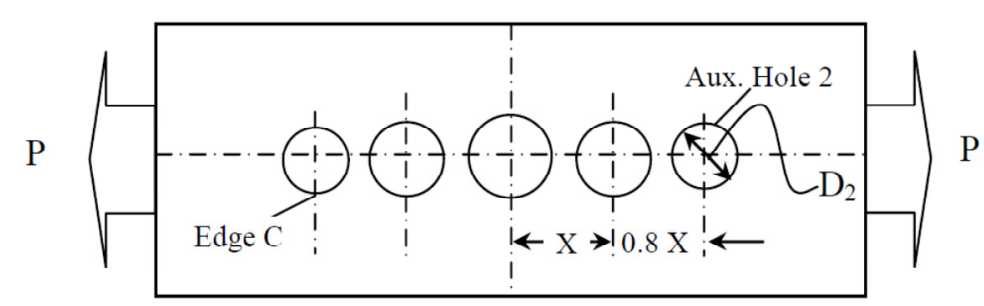

(c) Model $C$

Fig. 1: Details of three models analysed in this study.

\section{FINITE ELEMENT ANALYSIS}


An eight nodded quadrilateral element with element length of $1 \mathrm{~mm}$ was selected and used through out the study. Each node has two degrees of freedom, making a total 16 degrees of freedom per element. In order to construct the graphical image of the geometries of the different models of plate examined using the ANSYS (Advanced Engineering Simulation), it was necessary to input the basic geometric elements such as points, lines and arcs. Due to the symmetric nature of different models investigated, it was only necessary to discretize and analyse the one quarter of the problem of each model for finite element analysis. Main task in finite element analysis is selection of suitable element type. Number of checks and convergence test are made for selection of suitable element type from different available element. Results were then displayed by using post processor of ANSYS programme.

\section{RESULTS AND DISCUSSION}

Numerical results are presented for isotropic and orthotropic plates with central circular hole under in-plane static loading. The SCF is calculated on nominal area in all cases. The reduction in SCF is achieved firstly for isotropic plates and then work is extended for orthotropic plates.

\subsection{Isotropic Plate}

In the basic model (model $A$ ) maximum stress concentration is always occurred at the edges of main hole. At the edges of main hole; normal stress in $X$-direction $\left(\sigma_{\mathrm{x}}\right)$ is placed 3.003 times of $P$ and SCF (Calculate at nominal area) is appeared as 2.70 , which is very close to theoretical value of 2.72 .

Stress concentration at the edge $A$ is reduced by two coaxial auxiliary holes of diameter $D_{l}$ in model $B$. The analysis for reduction in stress concentration at the edges of main hole has been done for different centre distances of main hole and auxiliary hole 1 . It was very necessary to analyse, the influence of auxiliary holes on stress concentration around main hole as well as around of auxiliary holes.

In model $B$, edges of main hole (edge $A$ ) and edges of auxiliary hole 1 (edge $B$ ) are zone of stress concentration. Table 1 shows the effect of $D_{l} / D$ on $\sigma_{\mathrm{x}} / P$ at the edges $A$ and $B$ for $X / D=1.2,1.5,1.8$ and 2.0 respectively in model $B$. For all cases of $X / D$, results illustrate clearly that increasing $D_{1} / D$ results in continuously reduction of stress concentration at the edges of main hole, but this is also accompanied by an increase in stress concentration at the edges of auxiliary holes.

The following observations can be made from Table 1 . For $X / D=1.2$; increasing $D_{1} / D$ from 0.4 to 0.85 results in reduction of $\sigma_{\mathrm{x}} / P$ at edge $A$ from 2.895 to 2.451 , this is also accompanied by an increase of $\sigma_{\mathrm{x}} / P$ at edge $B$ from 2.058 to 2.435 . But when $D_{1} / D$ increases from 0.85 to $0.86, \sigma_{\mathrm{x}} / P$ is increased from 2.435 to 2.441 at edge $B$ and attained more than $\sigma_{\mathrm{x}} / P$ at edge $A$ i.e. maximum value of $\sigma \mathrm{x}$ is shifted from edge $A$ to edge $B$. The critical value of $D_{1} / D$ is 0.85 for this case.

Table 1: Variation of $\sigma_{\mathrm{x}} / P$ at the edges of main hole and auxiliary hole 1 with $D_{1} / D$ for different values of $X / D$ in model $B$. 
IIUM Engineering Journal, Vol. 12, No. 6, 2011: Special Issue in Science and Ethics

Jain

\begin{tabular}{|c|c|c|c|c|c|c|c|c|c|c|c|}
\hline \multicolumn{3}{|c|}{$X / D=1.2$} & \multicolumn{3}{|c|}{$X / D=1.5$} & \multicolumn{3}{|c|}{$X / D=1.8$} & \multicolumn{3}{|c|}{$X / D=2.0$} \\
\hline$D_{1} / D$ & $\begin{array}{c}\text { Edge } \\
A\end{array}$ & $\begin{array}{c}\text { Edge } \\
B\end{array}$ & $D_{1} / D$ & $\begin{array}{c}\text { Edge } \\
\boldsymbol{A}\end{array}$ & $\begin{array}{c}\text { Edge } \\
B\end{array}$ & $D_{1} / D$ & $\begin{array}{c}\text { Edge } \\
A\end{array}$ & $\begin{array}{c}\text { Edge } \\
B\end{array}$ & $D_{1} / D$ & $\begin{array}{c}\text { Edge } \\
\boldsymbol{A}\end{array}$ & $\begin{array}{c}\text { Edge } \\
B\end{array}$ \\
\hline 0.40 & 2.895 & 2.058 & 0.40 & 2.892 & 2.320 & 0.40 & 2.904 & 2.503 & 0.40 & 2.912 & 2.598 \\
\hline 0.60 & 2.747 & 2.215 & 0.60 & 2.751 & 2.439 & 0.60 & 2.779 & 2.581 & 0.60 & 2.800 & 2.645 \\
\hline 0.80 & 2.521 & 2.407 & 0.80 & 2.551 & 2.507 & 0.70 & 2.698 & 2.589 & 0.70 & 2.728 & 2.660 \\
\hline 0.84 & 2.466 & 2.436 & 0.82 & 2.530 & 2.523 & 0.74 & 2.663 & 2.606 & 0.76 & 2.681 & 2.666 \\
\hline 0.85 & 2.451 & 2.435 & 0.84 & 2.505 & 2.537 & 0.78 & 2.626 & 2.600 & 0.78 & 2.664 & 2.661 \\
\hline 0.86 & 2.437 & 2.441 & ----- & ----- & ----- & 0.80 & 2.607 & 2.609 & 0.80 & 2.646 & 2.661 \\
\hline
\end{tabular}

If $D_{1} / D$ increases beyond critical value, maximum stress concentration occurs at edge B and increases with increase of $D_{1} / D$. For $X / D=1.5$; increasing $D_{1} / D$ from 0.4 to 0.82 results in reduction of $\sigma_{\mathrm{x}} / P$ at edge $A$ from 2.892 to 2.530 , this is also accompanied by an increase of $\sigma_{\mathrm{x}} / P$ at edge $B$ from 2.320 to 2.523 . But when $D_{1} / D$ increases from 0.82 to $0.84, \sigma_{\mathrm{x}} / P$ is increased from 2.523 to 2.537 at edge $B$ and attained more than $\sigma_{\mathrm{x}} / P$ at edge $A$ i.e. maximum value of $\sigma_{\mathrm{x}}$ is shifted from edge $A$ to edge $B$. The critical value of $D_{l} / D$ is 0.82 for this case.

For $X / D=1.8$; increasing $D_{1} / D$ from 0.4 to 0.78 results in reduction of $\sigma_{\mathrm{x}} / P$ at edge $A$ from 2.904 to 2.626 , this is also accompanied by an increase of $\sigma_{\mathrm{X}} / P$ at edge $B$ from 2.503 to 2.600. But when $D_{l} / D$ increases from 0.78 to $0.80, \sigma_{\mathrm{x}} / P$ is increased from 2.600 to 2.609 at edge $B$ and attained more than $\sigma_{\mathrm{x}} / P$ at edge $A$ i.e. maximum value of $\sigma_{\mathrm{x}}$ is shifted from edge $A$ to edge $B$. The critical value of $D_{1} / D$ is 0.78 for this case.

For $X / D=2.0$; increasing $D_{1} / D$ from 0.4 to 0.78 results in reduction of $\sigma_{\mathrm{x}} / P$ at edge $A$ from 2.912 to 2.664 , this is also accompanied by an increase of $\sigma_{x} / P$ at edge $B$ from 2.598 to 2.661. But when $D_{1} / D$ increases from 0.78 to $0.80, \sigma_{\mathrm{x}} / P$ at edge $B$ is attained more than at edge $A$ i.e. maximum value of $\sigma_{\mathrm{x}}$ is shifted from edge $A$ to edge $B$. The critical value of $D_{1} / D$ is 0.78 for this case.

Table 2 shows the effect of $D_{1} / D$ and $D_{2} / D$ on $\sigma_{\mathrm{X}} / P$ at the edges $A, B$ and $C$ for $X / D=1.2,1.5,1.8$ and 2.0 respectively in model $C$. For all cases of $X / D$, Model $C$ is prepared by creating two more coaxial auxiliary holes in model $B$ (with critical value of $\left.D_{1} / D\right)$.

The following observations can be made from Table 2. For $X / D=1.2$; increasing $D_{2} / D$ from 0.4 to 0.74 , while maintaining the $D_{1} / D$ unchanged as 0.85 (critical value in model $B$ ), results in reduction of $\sigma_{\mathrm{x}} / P$ at edge $A$ from 2.434 to 2.359 , this is also accompanied by a decrease of $\sigma_{\mathrm{x}} / P$ at edge $B$ from 2.362 to 2.142 and an increase of $\sigma_{\mathrm{x}} / P$ at edge $C$ from 1.943 to 2.343 . But when $D_{2} / D$ increases beyond $0.74, \sigma_{\mathrm{x}} / P$ at edge $C$ is attained more than $\sigma_{\mathrm{x}} / P$ at edge $A$ i.e. maximum value of $\sigma \mathrm{x}$ is shifted from edge $A$ to edge $C$. Again, increasing $D_{1} / D$ from 0.85 to 0.92 , while maintaining the $D_{2} / D$ unchanged as 0.74 , results in reduction of $\sigma_{\mathrm{x}} / P$ at edge $A$ from 2.359 to 2.271 , this is also accompanied by an increase of $\sigma_{\mathrm{x}} / P$ at edge $B$ from 2.142 to 2.241 and a decrease of $\sigma_{\mathrm{x}} / P$ at edge $C$ from 2.343 to 2.255 .

For $X / D=1.5$; increasing $D_{2} / D$ from 0.4 to 0.7 , while maintaining the $D_{1} / D$ unchanged as 0.82 (critical value in model $B$ ), results in reduction of $\sigma_{\mathrm{x}} / P$ at edge $A$ from 2.507 to 2.454 , this is also accompanied by a decrease of $\sigma_{\mathrm{x}} / P$ at edge $B$ from 2.440 to 2.226 and an increase of $\sigma_{\mathrm{x}} / P$ at edge $\mathrm{C}$ from 2.226 to 2.448 . But when $D_{2} / D$ increases beyond $0.7, \sigma_{\mathrm{x}} / P$ 
at edge $C$ is attained more than $\sigma_{\mathrm{x}} / P$ at edge $A$ i.e. maximum value of $\sigma \mathrm{x}$ is shifted from edge $A$ to edge $C$. Again, increasing $D_{1} / D$ from 0.82 to 0.90 , while maintaining the $D_{2} / D$ unchanged as 0.7 , results in reduction of $\sigma x / P$ at edge $A$ from 2.454 to 2.369 , this is also accompanied by an increase of $\sigma x / P$ at edge $B$ from 2.226 to 2.330 and a decrease of $\sigma x / P$ at edge $C$ from 2.448 to 2.365 .

For $X / D=1.8$; increasing $D_{2} / D$ from 0.4 to 0.6 , while maintaining the $D_{1} / D$ unchanged as 0.78 (critical value in model $B$ ), results in reduction of $\sigma_{\mathrm{x}} / P$ at edge $A$ from 2.603 to 2.574 , this is also accompanied by a decrease of $\sigma_{\mathrm{x}} / P$ at edge $B$ from 2.520 to 2.421 and an increase of $\sigma \mathrm{x} / \mathrm{P}$ at edge $\mathrm{C}$ from 2.461 to 2.563 . But when $\mathrm{D}_{2} / \mathrm{D}$ increases beyond $0.6, \sigma x / P$ at edge $C$ is attained more than $\sigma_{\mathrm{x}} / P$ at edge $A$ i.e. maximum value of $\sigma_{\mathrm{x}}$ is shifted from edge $A$ to edge $C$. Again, increasing $D_{1} / D$ from 0.78 to 0.88 , while maintaining the $D_{2} / D$ unchanged as 0.6 , results in reduction of $\sigma_{\mathrm{x}} / P$ at edge $A$ from 2.574 to 2.482 , this is also accompanied by an increase of $\sigma_{\mathrm{x}} / P$ at edge $B$ from 2.421 to 2.474 and a decrease of $\sigma_{\mathrm{x}} / P$ at edge $C$ from 2.563 to 2.457 .

Table 2:

Variation of $\sigma_{\mathrm{x}} / P$ at the edges of main hole, auxiliary hole 1 and auxiliary hole 2 with $D_{1} / D$ and $D_{2} / D$ for different values of $X / D$ in model $C$.

\begin{tabular}{|c|c|c|c|c|c|}
\hline$X / D$ & $D_{I} / D$ & $D_{2} / D$ & Edge $A$ & Edge $B$ & Edge $C$ \\
\hline \multirow[t]{7}{*}{1.2} & 0.85 & 0.40 & 2.434 & 2.362 & 1.943 \\
\hline & 0.85 & 0.60 & 2.400 & 2.257 & 2.181 \\
\hline & 0.85 & 0.70 & 2.371 & 2.181 & 2.281 \\
\hline & 0.85 & 0.74 & 2.359 & 2.142 & 2.343 \\
\hline & 0.88 & 0.74 & 2.324 & 2.195 & 2.297 \\
\hline & 0.90 & 0.74 & 2.298 & 2.205 & 2.282 \\
\hline & 0.92 & 0.74 & 2.271 & 2.241 & 2.255 \\
\hline \multirow[t]{6}{*}{1.5} & 0.82 & 0.40 & 2.507 & 2.440 & 2.226 \\
\hline & 0.82 & 0.60 & 2.476 & 2.333 & 2.400 \\
\hline & 0.82 & 0.70 & 2.454 & 2.226 & 2.448 \\
\hline & 0.84 & 0.70 & 2.433 & 2.279 & 2.415 \\
\hline & 0.86 & 0.70 & 2.413 & 2.308 & 2.411 \\
\hline & 0.90 & 0.70 & 2.369 & 2.330 & 2.365 \\
\hline \multirow[t]{6}{*}{1.8} & 0.78 & 0.40 & 2.603 & 2.520 & 2.461 \\
\hline & 0.78 & 0.60 & 2.574 & 2.421 & 2.563 \\
\hline & 0.80 & 0.60 & 2.557 & 2.431 & 2.537 \\
\hline & 0.82 & 0.60 & 2.539 & 2.440 & 2.518 \\
\hline & 0.86 & 0.60 & 2.502 & 2.467 & 2.474 \\
\hline & 0.88 & 0.60 & 2.482 & 2.474 & 2.457 \\
\hline \multirow[t]{3}{*}{2.0} & 0.78 & 0.40 & 2.642 & 2.587 & 2.585 \\
\hline & 0.78 & 0.50 & 2.631 & 2.539 & 2.583 \\
\hline & 0.78 & 0.56 & 2.623 & 2.514 & 2.616 \\
\hline
\end{tabular}


IIUM Engineering Journal, Vol. 12, No. 6, 2011: Special Issue in Science and Ethics

\begin{tabular}{|l|l|l|l|l|l|}
\hline 0.80 & 0.56 & 2.606 & 2.521 & 2.599 \\
& 0.82 & 0.56 & 2.590 & 2.532 & 2.579 \\
& 0.84 & 0.56 & 2.574 & 2.539 & 2.542 \\
& 0.86 & 0.56 & 2.556 & 2.546 & 2.536 \\
\hline
\end{tabular}

For $X / D=2.0$; increasing $D_{2} / D$ from 0.4 to 0.56 , while maintaining the $D_{1} / D$ unchanged as 0.78 (critical value in model $B$ ), results in reduction of $\sigma_{\mathrm{x}} / P$ at edge $A$ from 2.642 to 2.623 , this is also accompanied by a decrease of $\sigma_{\mathrm{x}} / P$ at edge $B$ from 2.587 to 2.514 and an increase of $\sigma_{x} / P$ at edge $C$ from 2.585 to 2.616 . But when $D_{2} / D$ increases beyond $0.56, \sigma_{\mathrm{x}} / P$ at edge $C$ is attained more than $\sigma_{\mathrm{x}} / P$ at edge $A$ i.e. maximum value of $\sigma_{\mathrm{x}}$ is shifted from edge $A$ to edge $C$. Again, increasing $D_{1} / D$ from 0.78 to 0.86 , while maintaining the $D_{2} / D$ unchanged as 0.56 , results in reduction of $\sigma_{\mathrm{x}} / P$ at edge $A$ from 2.623 to 2.556 , this is also accompanied by an increase of $\sigma_{x} / P$ at edge $B$ from 2.514 to 2.546 and a decrease of $\sigma_{\mathrm{x}} / P$ at edge $C$ from 2.616 to 2.536 .

Figure 2 illustrates the variation of SCF at the edges of main hole (edge $A$ ) in model $B$ and $C$ with $D_{1} / D$ for different values of $X / D$. These are maximum SCF in plate, attaining at the edges of main hole.
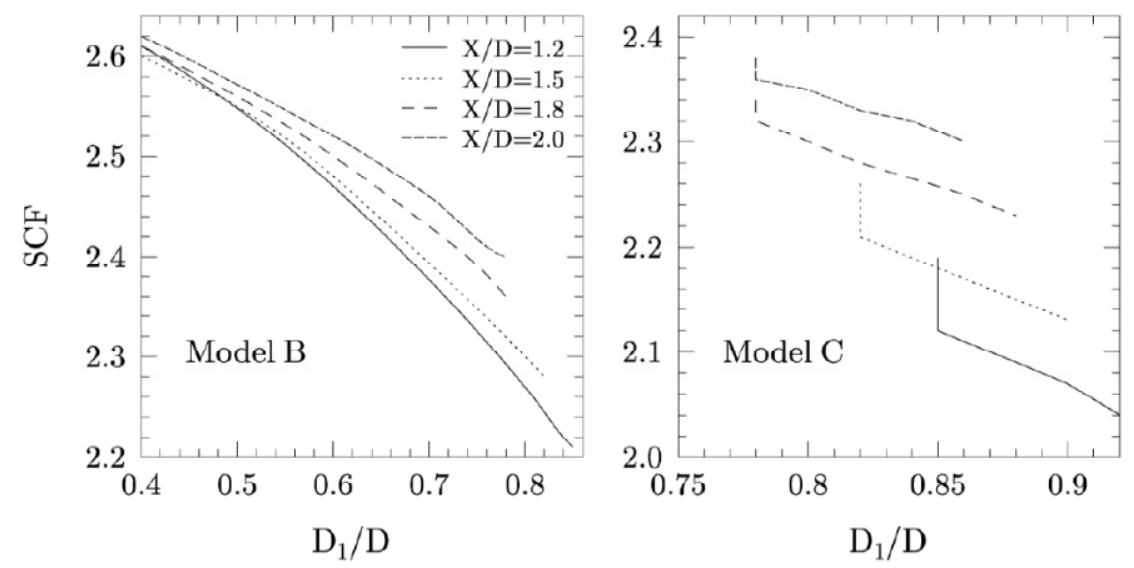

Fig. 2: Effects of $D_{1} / D$ on SCF at the edges of main hole (edge A) in Model B and C.

In model $B, \mathrm{SCF}$ is reduced up to $2.21,2.28,2.36$ and 2.4 for $X / D=1.2,1.5,1.8$ and 2.0 respectively. Where, in model $\mathrm{C}, \mathrm{SCF}$ is reduced up to $2.04,2.13,2.23$ and 2.3 for $X / D$ $=1.2,1.5,1.8$ and 2.0 respectively.

Figure 3 shows the \% reduction in SCF at the edges of main hole in model $B$ and $C$ with $D_{1} / D$ for different values of $X / D$. In model $B ; 18.39,15.75,12.57$ and $11.31 \%$ reduction in $\mathrm{SCF}$ is achieved for $X / D=1.2,1.5,1.8$ and 2.0 respectively. 
IIUM Engineering Journal, Vol. 12, No. 6, 2011: Special Issue in Science and Ethics

Jain
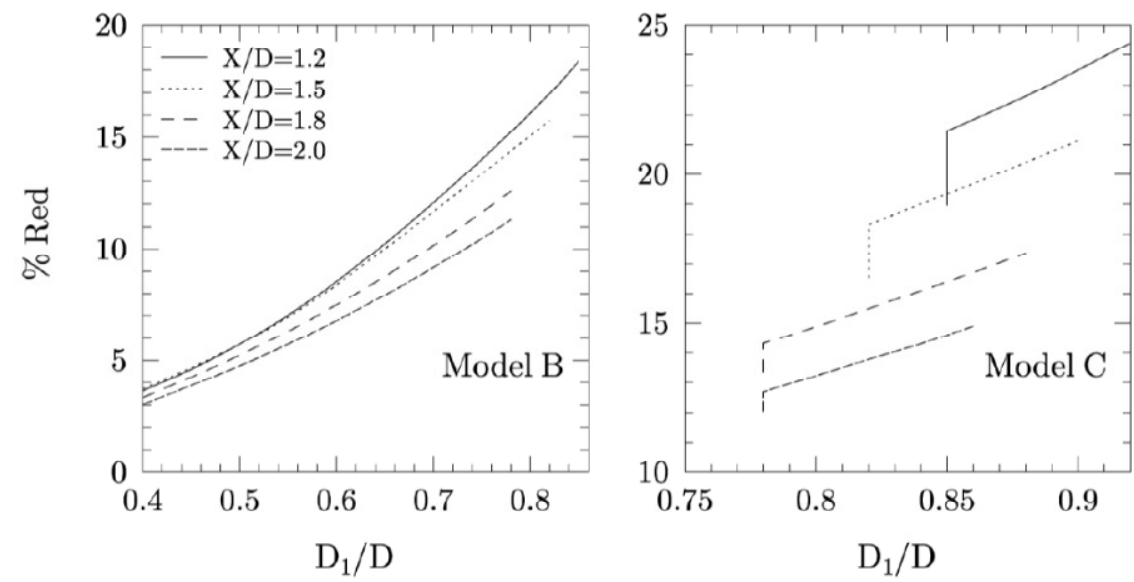

Fig. 3: Effects of $D_{1} / D$ on $\%$ reduction in SCF at the edges of main hole (edge A) in Model B and C.

Where, in model $C ; 24.39,21.13,17.36$ and $14.90 \%$ reduction in SCF is achieved for $X / D$ $=1.2,1.5,1.8$ and 2.0 respectively. Results indicate clearly that maximum possible $\%$ reduction in SCF in model $C$ is almost $6.0 \%$ greater than model $B$ for all values of $X / D$. It has been observed that maximum possible \% reduction in SCF decreases with increase of $X / D$ in model $B$ and $C$ both.

\subsection{Orthotropic Plate}

Thirteen different composite materials are selected for analysis of influence of auxiliary holes in model $B$ and $C$, upon reduction of stress concentration around main hole in an orthotropic plate.

SCF in model $A$ and \% reduction in SCF in model $B$ and $C$ for $X / D=1.2$ and 1.5 , are listed in Table 3. The elastic properties of different composite materials used in study are also listed in Table 3.

Table 3: SCF in model $A$ and achieved \% reduction in SCF in model $B$ and $C$ for orthotropic plates.

\begin{tabular}{|c|c|c|c|c|c|c|c|c|c|}
\hline \multirow{3}{*}{ Material Type } & \multirow{3}{*}{$\mathbf{E}_{1}$} & \multirow{3}{*}{$\mathbf{E}_{2}$} & \multirow{3}{*}{$\mathbf{G}_{12}$} & \multirow{3}{*}{$\mu$} & \multirow{3}{*}{ SCF } & \multicolumn{4}{|c|}{$\%$ Reduction in SCF } \\
\hline & & & & & & \multicolumn{2}{|c|}{$X / D=1.2$} & \multicolumn{2}{|c|}{$X / D=1.5$} \\
\hline & & & & & & $\begin{array}{c}\text { Model } \\
\boldsymbol{B}\end{array}$ & $\begin{array}{c}\text { Model } \\
C\end{array}$ & $\begin{array}{c}\text { Model } \\
\boldsymbol{B}\end{array}$ & $\begin{array}{c}\text { Model } \\
\quad C\end{array}$ \\
\hline E-glass/epoxy & 39 & 8.6 & 3.8 & 0.28 & 3.816 & 21.13 & 29.60 & 19.36 & 27.15 \\
\hline S-glass/epoxy & 43 & 8.9 & 4.5 & 0.27 & 3.789 & 21.20 & 29.58 & 19.40 & 27.10 \\
\hline Woven glass/epoxy & 29.7 & 29.7 & 5.3 & 0.17 & 3.169 & 19.83 & 27.11 & 17.61 & 24.23 \\
\hline Kelvar/epoxy & 87 & 5.5 & 2.2 & 0.34 & 5.017 & 18.70 & 29.42 & 17.73 & 27.95 \\
\hline Carbon/epoxy & 142 & 10.3 & 7.2 & 0.27 & 4.488 & 20.81 & 30.55 & 19.52 & 28.60 \\
\hline Carbon/PEEK & 131 & 8.7 & 5 & 0.28 & 4.696 & 20.11 & 30.27 & 18.96 & 28.51 \\
\hline Carbon/epoxy & 177 & 10.8 & 7.6 & 0.27 & 4.637 & 20.46 & 30.48 & 19.27 & 28.66 \\
\hline Carbon/polyimide & 216 & 5 & 4.5 & 0.25 & 5.384 & 17.97 & 29.15 & 17.18 & 27.95 \\
\hline
\end{tabular}


IIUM Engineering Journal, Vol. 12, No. 6, 2011: Special Issue in Science and Ethics

\begin{tabular}{|l|c|c|c|c|c|c|c|c|c|}
\hline Graphite/epoxy & 294 & 6.4 & 4.9 & 0.23 & 5.585 & 16.89 & 28.28 & 16.13 & 27.26 \\
Boron/epoxy & 201 & 21.7 & 5.4 & 0.17 & 4.889 & 18.80 & 29.36 & 17.77 & 27.83 \\
Boron/aluminum & 235 & 137 & 47 & 0.3 & 3.169 & 20.08 & 27.20 & 17.82 & 24.28 \\
$\mathrm{SiC} / \mathrm{Al}$ & 204 & 118 & 41 & 0.27 & 3.175 & 20.10 & 27.23 & 17.84 & 24.31 \\
$\mathrm{SiC} /$ ceramic & 121 & 112 & 44 & 0.2 & 2.783 & 18.73 & 24.95 & 16.17 & 21.74 \\
\hline
\end{tabular}

The reduction in SCF is calculated with critical value of $D_{1} / D$ and $D_{2} / D$ of isotropic plate. Following observations can be made from these results.

For $X / D=1.2$; in case of model $B$, reduction in SCF is between the range of 17 to $21 \%$ for all materials, maximum in case of S-glass/epoxy with $21.20 \%$ and minimum in case of Graphite/epoxy with $16.89 \%$.

In case of model $C$, reduction in SCF is between the range of 25 to $31 \%$ for all materials, maximum in case of Carbon/epoxy (AS4/3501-6) with $30.55 \%$ and minimum in case of Sic/ceramic with $24.95 \%$.

For $X / D=1.5$; in case of model $B$, reduction in SCF is between the range of 16 to $20 \%$ for all materials, maximum in case of Carbon/epoxy (AS4/3501-6) with $19.52 \%$ and minimum in case of Graphite/epoxy with $16.13 \%$.

In case of model $C$, reduction in SCF is between the range of 22 to $29 \%$ for all materials, maximum in case of Carbon/epoxy (IM6SC1081) with $28.66 \%$ and minimum in case of Sic/ceramic with $21.74 \%$.

\section{CONCLUSION}

The reduction in SCF depends on diameter and position of auxiliary holes in isotropic or orthotropic plates, two parameters $X / D$ and $D_{1} / D$ in model $B$ and three parameters $X / D$, $D_{1} / D$ and $D_{2} / D$ in model $C$ influence the reduction in SCF. For an isotropic plate; in case of model $C$, maximum reduction in SCF is achieved for $X / D=1.2$ as $24.39 \%$, where, in case of model $B$, maximum reduction in SCF is achieved for $X / D=1.2$ as $18.39 \%$ only. For a convenient design, for $X / D=1.5$, up to $21.13 \%$ reduction in SCF can be achieve in model $C$, but in case of model $\mathrm{B}$, it can be only $15.75 \%$. In case of orthotropic plate; maximum reduction in SCF is between the range of 25.0 to $31.0 \%$ for different materials in model $\mathrm{C}$, where in model $B$, maximum reduction in $\mathrm{SCF}$ is between the range of 17.0 to $21.0 \%$ for different materials. It has been observed that maximum possible $\%$ reduction in SCF decreases with increase of $X / D$ in model $B$ and $C$ both, for isotropic and orthotropic plates. It has been also seen that maximum possible reduction in SCF in an orthotropic plate depends on elastic constants. In case of orthotropic materials like Graphite epoxy, Kelvar/epoxy, carbon/polyimide, where SCF is approaching more than 5.0, reduction in SCF can be achieved more than $28.0 \%$ in model $C$, where in model $B$, reduction in SCF can be achieved up to $18.0 \%$ only. For an isotropic and an orthotropic plate, such reductions in maximum SCF improve fatigue life of component. It must be remembered that only three parameters $X / D, D_{1} / D$ and $D_{2} / D$ in model $C$ affect the reduction in SCF, and these should be selected as per requirement and convenience of designer. 


\section{REFERENCES}

[1] A Meguid. 'Finite element analysis of defence hole system for the reduction of stress concentration factor in a uni-axially loaded plate with two coaxial holes'. Engineering fracture mechanics, vol 25, issue 4, 1986, p 403.

[2] G S Giare and R Shabahang. 'The reduction of stress concentration around the hole in an isotropic plate using composite material'. Engineering Fracture Mechanics, vol 32, issue 5, $1989, \mathrm{p} 757$.

[3] C P Providakis and D A Sotiropoulos. 'A BEM approach to the stress concentration reduction in visco-plastic plates by multiple holes'. Computers \& structures, vol 64, issue 14, 1997, p 313.

[4] R T Tenchev, M K Nygard and A Echtermeyer. 'Design procedure for reducing the stress concentration around circular holes in laminated composites'. Composites, vol 26, 1995, p 815.

[5] N T Younis. 'Assembly stress for the reduction of stress concentration'. Mechanics research communications, vol 33, 2006, p 837.

[6] H Mahiou and A Bekaou. 'Local stress concentration and the prediction of tensile failure in unidirectional composites'. Composites science and technology, vol 57, 1997, p 1661.

[7] L Toubal, M Karama and B Lorrain. 'Stress concentration in a circular hole in composite plate'. Composite structures, vol 68, 2005, p 31.

[8] $\mathrm{H} \mathrm{C} \mathrm{Wu}$ and $\mathrm{B} \mathrm{Mu}$. 'On stress concentrations for isotropic/orthotropic plates and cylinders with a circular hole'. Composites: part B, vol 34, 2003, p 127.

[9] V G Ukadgaonker and D K N Rao. 'A general solution for stress around holes in symmetric laminates under in-plane loading'. Composite structure, vol 49, 2000, p 339.

[10] K Ting, K T Chen and W S Yang. 'Stress analysis of the multiple circular holes with the rhombic array using alternating method'. International journal of pressure vessels and piping, vol 76, 1999, p 503.

[11] R A Chaudhuri. 'Stress concentration around a part through hole weakening laminated plate'. Computers and structures, vol 27, issue 5, 1987, p 601.

[12] T K Paul and K M Rao. 'Stress analysis in circular holes in FRP laminates under transverse load'. Computers and structures, vol 33, issue 4, 1989, p 929.

[13] G B Sinclair. 'On the effect on stress concentration of rounding the edge of a hole through plate'. International Journal of Mechanical Sciences, vol 22, issue 12, 1980, p 731.

[14] N Troyani, C Gomes and G Sterlacci. 'Theoretical stress concentration factors for short rectangular plates with centered circular holes'. Transactions of ASME Journal of Mechanical Design, vol 124, 2002, p 126.

[15] T Iwaki. 'Stress concentrations in a plate with two unequal circular holes'. International Journal of engineering Sciences, vol 18, issue 8, 1980, p 1077.

[16] T K Paul and K M Rao. 'Finite element evaluation of stress concentration factor of thick laminated plates under transverse loading'. Computers and Structures, vol 48, issue 2, 1993, p 311.

[17] M Fillipini. 'Stress Gradient calculations at notches'. International Journal of Fatigue, vol 22, issue 5, 2000, p 397.

[18] X Xiwu, S Liangxin and F Xuqi. 'Stress concentration of finite composite laminates with elliptical hole'. Computers \& structures, vol 57, issue 1, 1995, p 29.

[19] X Xiwu, S Liangxin and F Xuqi. 'Stress concentration of finite composite laminates weakened by multiple elliptical holes'. International journal of solids structures, vol 32, issue 20, 1995, p 3001.

[20] R E Peterson. 'Stress concentration design factors'. John Wiley and sons, New York, 1966.

[21] I M Daniel and O Ishai. 'Engineering mechanics of composite materials'. Oxford University Press, New York, 1994.

[22] C T F Ross. 'Advance finite element methods'. Horwood Publishing Limited, Chichester, 1998. 